Correspondence

K. Solomon

katie.solomon@ucd.ie

Received 5 January 2011

Accepted 28 March 2011

\section{An investigation of the subtype diversity of clinical isolates of Irish Clostridium difficile ribotypes 027 and 078 by repetitive-extragenic palindromic PCR}

\author{
K. Solomon, ${ }^{1}$ S. Murray, ${ }^{1}$ L. Scott, ${ }^{2}$ S. McDermott, ${ }^{2}$ D. Drudy, ${ }^{1}$ A. Martin, ${ }^{1,3}$ \\ C. O'Donoghue, ${ }^{1,3}$ M. Skally, ${ }^{2,4}$ K. Burns, ${ }^{5}$ L. Fenelon, ${ }^{2}$ F. Fitzpatrick, ${ }^{4,5}$ \\ L. Kyne ${ }^{1,3}$ and S. Fanning ${ }^{1}$
}

${ }^{1}$ UCD Veterinary Sciences Centre, University College Dublin, Belfield, Dublin 4, Ireland

${ }^{2}$ Department of Clinical Microbiology, St Vincent's University Hospital, Elm Park, Dublin 4, Ireland

${ }^{3}$ Department of Medicine for the Older Person, Mater Misericordiae University Hospital, Eccles Street, Dublin 7, Ireland

${ }^{4}$ Health Protection and Surveillance Centre, Gardiner Street, Dublin 1, Ireland

${ }^{5}$ Department of Clinical Microbiology, Beaumont Hospital, Beaumont Road, Dublin 9, Ireland

\begin{abstract}
A repetitive-extragenic palindromic PCR (rep-PCR) subtyping method (DiversiLab) in conjunction with ribotyping, toxinotyping and antimicrobial-susceptibility testing was used to detect subtypes within Clostridium difficile ribotypes 027 and 078. Clinical isolates of ribotypes 027 (toxinotype III) $(n=30)$ and 078 (toxinotype V) $(n=23)$ were provided by health-care facilities across the Republic of Ireland over 2 months in 2006 and 1 month in 2009. Ribotype 027 isolates were significantly more related to each other (9 different subtype profiles) when compared to ribotype 078 isolates ( 14 different profiles) $(P=0.001$; cut-off $>90 \%$ similarity). Almost half of ribotype 078 isolates $(45.5 \%)$ showed no relationship to each other. The clonality of ribotype 027 isolates suggests effective adaptation to the human niche, whereas the considerable genetic diversity within ribotype 078 isolates suggests that they may have originated from a variety of sources. Subtyping correlated well with antimicrobial susceptibility, in particular clindamycin susceptibility for ribotype 027 , but diverse antimicrobial-susceptibility profiles were seen in ribotype 078 isolates, even within a single health-care facility. Between 2006 and 2009, a change in the predominant subtype of ribotype 027 was seen, with the recent clone representing half of all ribotype 027 isolates studied. This strain exhibited $89 \%$ similarity to a rep-PCR profile of the North American NAP-1 strain.
\end{abstract}

\section{INTRODUCTION}

Clostridium difficile infection (CDI) is recognized as a major cause of health-care-acquired antibiotic-associated diarrhoea and pseudomembranous colitis. Several molecular typing methods have been employed to study $C$. difficile, e.g. PCR ribotyping, PFGE, multilocus variable number tandem repeat analysis (MLVA) and repetitiveextragenic palindromic PCR (rep-PCR), each with various advantages and disadvantages (Killgore et al., 2008; Kuijper et al., 2009). rep-PCR profiling relies on variations in the copy number and location of repetitive elements dispersed

Abbreviations: CDI, Clostridium difficile infection; HPSC-HSE, Health Protection Surveillance Centre and Health Service Executive; $M L S_{B}$, macrolide-lincosamide-streptogramin B; MLVA, multilocus variable number tandem repeat analysis; rep-PCR, repetitive-extragenic palindromic PCR. throughout the genome. PCR amplification between these elements results in DNA amplicons of various sizes and frequencies giving rise to individual rep-PCR profiles. Discrimination of subtypes within ribotypes by rep-PCR (Northey et al., 2005; Rahmati et al., 2005; Spigaglia \& Mastrantonio, 2003), randomly amplified polymorphic DNA techniques (Fawley et al., 2003) and a commercially available semi-automated rep-PCR system (DiversiLab, Bacterial Barcodes; bioMérieux) has been useful for further studying $C$. difficile epidemiology and these methods have shown good reproducibility for this organism (Healy et al., 2005; Pasanen et al., 2011; Spigaglia \& Mastrantonio, 2003).

Reports of CDI have been increasingly associated with a hypervirulent strain, PCR ribotype 027 [PFGE type NAP-1 (North American pulsotype-1)] (Kuijper et al., 2006, 2007; McDonald et al., 2005). Studies of ribotype 027/NAP-1 epidemiology using different molecular subtyping methods 
have identified some clonal strains (Killgore et al., 2008), whereas others have distinguished hospital-related clusters (Fawley et al., 2008). The spread of ribotype 027/NAP-1 mainly correlates with resistance to fluoroquinolones, although outbreaks caused by less common clindamycinresistant strains have occurred (Johnson et al., 1999; Kuijper et al., 2008), with the first European cases reported in Ireland (Drudy et al., 2008). MLVA of these isolates differentiated distinct clindamycin-resistant and -susceptible clusters, despite the geographical proximity of the sources (Drudy et al., 2008).

A recently emerging PCR ribotype, 078 (PFGE type NAP-7 or -8), has been identified in food and environmental sources, and is associated with community-acquired infections (Jhung et al., 2008; Keel et al., 2007). Prevalence of this strain is increasing in Europe (Brazier et al., 2008; Debast et al., 2009; Goorhuis et al., 2008a, b; Keel et al., 2007; Rupnik et al., 2008). The increase in the prevalence of ribotype 078 appears to have mirrored a reduction in the prevalence of ribotype 027 in The Netherlands (Hensgens et al., 2009). In a recent national study in Ireland, ribotype 078 accounted for $9.4 \%$ of isolates, whereas ribotype 027 accounted for $18.7 \%$ $(n=107)$ (Burns et al., 2010b). Antimicrobial-susceptibility patterns of ribotype 078 isolates are less well documented. In a recent study in The Netherlands it was reported that isolates cultured from pigs exhibited identical susceptibility patterns and a genetic relationship to human isolates suggesting possible animal-to-human transmission (zoonosis) (Debast et al., 2009). Human-to-human transmission of ribotype 078 strains is less well characterized, although it has been suggested during a recent outbreak of CDI due to ribotype 078 in the Republic of Ireland (Burns et al., 2010a).

The distinctive differences in genetic diversity, infection origin and antimicrobial susceptibility between $C$. difficile ribotypes 027 and 078 highlight the importance of an epidemiological study of circulating ribotype 027 and 078 strains. One approach, stratifying antimicrobial-susceptibility profiles with enhanced genotyping, may identify subtypes specific to health-care settings, facilitate monitoring of their potential for spread and track the emergence of multi-resistant, increasingly virulent strains of ribotype 078 in the human population.

\section{METHODS}

Bacterial isolates and patient clinical history. A total of 53 wellcharacterized isolates of $C$. difficile ribotypes $027(n=30)$ and 078 $(n=23)$ were selected from isolates previously collected from patients with CDI in 14 hospitals across the Republic of Ireland (Fig. 1) during 2 months in $2006(n=10)$ and 1 month in $2009(n=43)$. Ribotypes 027 and 078 comprised 37.7 and $1.9 \%$, respectively, of all C. difficile strains isolated in 2006, and 18.7 and $9.4 \%$, respectively, of all 2009 isolates (Burns et al., 2010b). Clinical details were collected from patients, including origin of infection as defined by Kuijper et al. (2006).

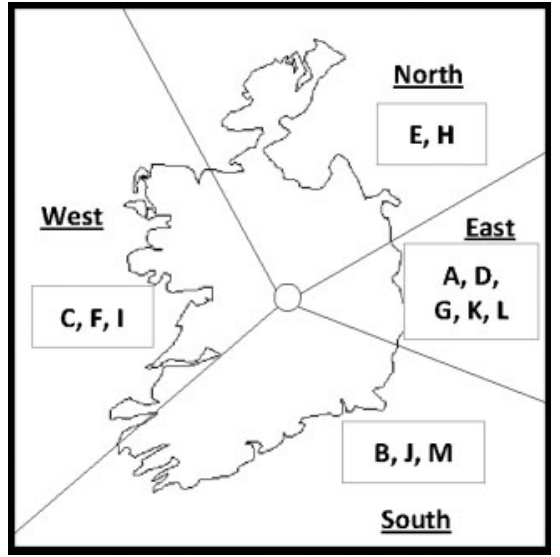

Fig. 1. A schematic map of the Republic of Ireland indicating health-care facilities included in this study. Clinical C. difficile isolates in this study were collected from health-care facilities from a variety of geographical locations. The facilities have been coded $(\mathrm{A}-\mathrm{M})$ and are separated into their geographical regions for illustration of proximity.

Antimicrobial-susceptibility testing. Antimicrobial susceptibility to $\mathrm{MLS}_{\mathrm{B}}$ (macrolide-lincosamide-streptogramin B) antibiotics (clindamycin and erythromycin), fluoroquinolones (ciprofloxacin, levofloxacin and moxifloxacin), metronidazole and vancomycin were determined by the Etest method (bioMérieux). Isolates of standardized McFarland inoculum were streaked onto pre-reduced Brucella agar plates supplemented with vitamin $\mathrm{K} 1$, haemin and $5 \%(\mathrm{v} / \mathrm{v})$ sheep blood (BD Biosciences). Etest strips were laid directly on the agar surface and incubated at $37^{\circ} \mathrm{C}$ for $48 \mathrm{~h}$. The MIC $\left(\mu \mathrm{g} \mathrm{ml}^{-1}\right)$ for all antibiotics was measured at the ellipse of inhibited growth. Breakpoints of susceptibility for moxifloxacin, clindamycin and erythromycin were defined by reference to the Clinical and Laboratory Standards Institute (CLSI, 2007) and those for ciprofloxacin and levofloxacin were defined by reference to the European Committee on Antimicrobial Susceptibility Testing (www.eucast.org -2010 , v. 2.6).

DNA purification. Genomic DNA was purified from bacterial pellets following overnight anaerobic growth in Schaedler anaerobe broth (Oxoid) at $37^{\circ} \mathrm{C}$. After enzymic lysis of cell walls, DNA was extracted using the Wizard genomic DNA purification kit (Promega) and assessed for concentration and purity with a NanoDrop spectrophotometer (Thermo Scientific) before use in PCR.

PCR ribotyping. Isolates were characterized as ribotype 027 or 078 by 16-23S intergenic-spacer PCR performed using the method outlined by Stubbs et al. (1999). Gel electrophoresis fingerprints were analysed using BioNumerics software (version 6.01; Applied Maths) and ribotypes were assigned by comparison to reference strains from the Leiden University Medical Centre library, Leiden, The Netherlands.

Toxinotyping. Isolates were toxinotyped as described by Rupnik et al. (1998). DNA amplicons generated by PCR of the first $3 \mathrm{~kb}$ of the toxin $\mathrm{B}$ gene $(\mathrm{B} 1)$ and $3 \mathrm{~kb}$ of the $\mathrm{C}$-terminal region of the toxin $\mathrm{A}$ gene (A3) were digested by restriction enzymes HincII, AccI and EcoRI producing characteristic banding patterns.

rep-PCR DNA fingerprinting. Genomic DNA was amplified using the DiversiLab Clostridium kit (Bacterial Barcodes; bioMérieux) 
according to the manufacturer's instructions and as described by Pasanen et al. (2011). Positive and negative controls (supplied in the kit) were included and assessed in parallel to validate the reaction.

DNA amplicons were separated on microfluidics chips (DNA LabChip device; Caliper Technologies) using a 2100 Bioanalyser (Agilent Technologies) (Healy et al., 2005). DNA standard markers were used to normalize sample runs and a molecular ladder (2004000 bp marker provided with kit) was included. Data interpretation and analysis were carried out within the DiversiLab software (version 3.4) utilizing dendrograms, similarity matrices and virtual gel images generated from fluorescence intensity graphs after normalization. Percentage similarities between virtual gels generated from isolates were calculated using the Kullback-Liebler band-based method, weighted on the presence or absence of bands.

The basis for discrimination between strains was defined by the DiversiLab strain typing analysis guide (provided online with the software) parameters as follows: similarity greater than $97 \%$ was defined as indistinguishable; similarity greater than $95 \%$ was defined as similar; similarity less than $95 \%$ was considered different but related; and similarity less than $90 \%$ was considered unrelated. Subtypes were assigned where two or more isolates exhibited greater than $90 \%$ similarity to each other. Statistical significance was calculated using $\chi^{2}$ and Fisher's exact tests.

\section{RESULTS AND DISCUSSION}

\section{Characterization of isolates}

Isolates were characterized by PCR ribotyping as either ribotype 027 or 078 . Toxinotyping confirmed that all isolates of ribotype 078 were toxinotype V. Ribotype 027 isolates were confirmed as toxinotype III.

All isolates were found to be susceptible to both metronidazole and vancomycin (MIC ranges of $0.25-1.5$ and $0.0064-0.38 \mu \mathrm{g} \mathrm{ml}^{-1}$, respectively) and resistant to ciprofloxacin (MIC range 8 to $>32 \mu \mathrm{g} \mathrm{ml}^{-1}$ ). Antimicrobialresistance profiles were assigned to isolates based on patterns of susceptibility in response to fluoroquinolones, moxifloxacin, levofloxacin and the $\mathrm{MLS}_{\mathrm{B}}$ antibiotics (erythromycin and clindamycin). Susceptibility profiles ranged from resistance to all fluoroquinolone and $\mathrm{MLS}_{\mathrm{B}}$ antimicrobials (denoted as profile 1) to susceptibility to erythromycin only (denoted as profile 9).

\section{Diversity of isolates as defined by rep-PCR subtyping}

rep-PCR fingerprints for isolates characterized as ribotypes 027 and 078 were generated, and subsequent dendrograms were created and analysed. At a cut-off point of $>90 \%$ similarity, four main subtypes within ribotype 027 could be identified (Fig. 2), one of which (denoted subtype 1) contained half of all ribotype 027 isolates analysed. Isolates within this subtype originated from health-care facilities in all geographically distinct regions, thus confirming clonal spread within our study population and that this subtype may therefore exhibit a competitive genetic fitness over others in the current health-care environment nationwide. A comparison between the virtual gel fingerprint profiles of study isolates and those in a commercially provided 'DiversiLab C. difficile library' confirmed that isolates of rep-PCR subtype 1 were $89 \%$ similar to a North American pulsotype-1 (NAP-1) isolate (McDonald et al., 2005) (data not shown). Similarities between European ribotype 027 isolates and North American strains have been shown by PFGE (Fawley et al., 2008; Smith, 2005). The predominant subclone of ribotype 027 in Ireland is related to the hypervirulent NAP-1 epidemic strain; however, other subtypes exist that are unrelated.

The remaining ribotype 027 isolates clustered within three different rep-PCR subtypes unrelated to the predominant clone. These lesser subtypes may not have been able to dominate due to certain characteristics, such as a slower growth rate, reduced sporulation/environmental persistence or reduced toxin production/virulence, and were either from the same hospital (subtype 4) or neighbouring regions (subtype 3 ) suggesting a reduced ability to spread. Five isolates $(16 \%)$ were unrelated to either of these subtypes or to each other ( $<90 \%$ similarity).

Heterogeneity within ribotype 027 has been reported by others in European isolates (Fawley et al., 2008) and we postulate that ribotype 027 isolates may not have equal virulence potential, and the emphasis on diagnostic laboratories to identify isolates as markers of potential outbreaks by ribotyping alone may be of limited use.

Ribotype 027 isolates were significantly more likely to be related to each other (similarity $\geqslant 95 \%$ ) than ribotype 078 isolates $(P=0.001)$, which exhibited greater genetic diversity; $63 \%$ of ribotype 027 isolates were considered to be indistinguishable from at least one other ( $>97 \%$ similarity), compared to only $17 \%$ of ribotype 078 isolates. At a cut-off point of $>90 \%$ similarity, five main subtypes within ribotype 078 could be identified (Fig. 3), but $45.5 \%$ of ribotype 078 isolates were considered to be unrelated to each other.

The closest related ribotype 078 isolates originated from either the same health-care source (hospitals G and E) or health-care sources within the same region (hospitals $G$ and D). Isolates with a community-associated origin and from nursing homes were closely related to isolates from healthcare facilities in the locality, suggesting common sources of infection. Related isolates in subtype 2, however, originated from geographically distinct facilities ( $>400 \mathrm{~km}$ away). Subtype diversity was seen between isolates from health-care facilities of close geographical proximity (within a $15 \mathrm{~km}$ radius; hospitals G, A and L). Variation between human ribotype 078/toxinotype $\mathrm{V}$ isolates has also been confirmed by PFGE analysis ( SmaI digestion) with isolates grouped into approximately seven distinct clusters of $<90 \%$ similarity including PFGE types NAP-7 and NAP-8 (Jhung et al., 2008).

Other studies using rep-PCR as well as other typing methods have identified that ribotype 078/toxinotype V isolates show a degree of relatedness, in contradiction to the findings presented here (Lin et al., 2011; Pasanen et al., 2011). However, these studies involved either a small 


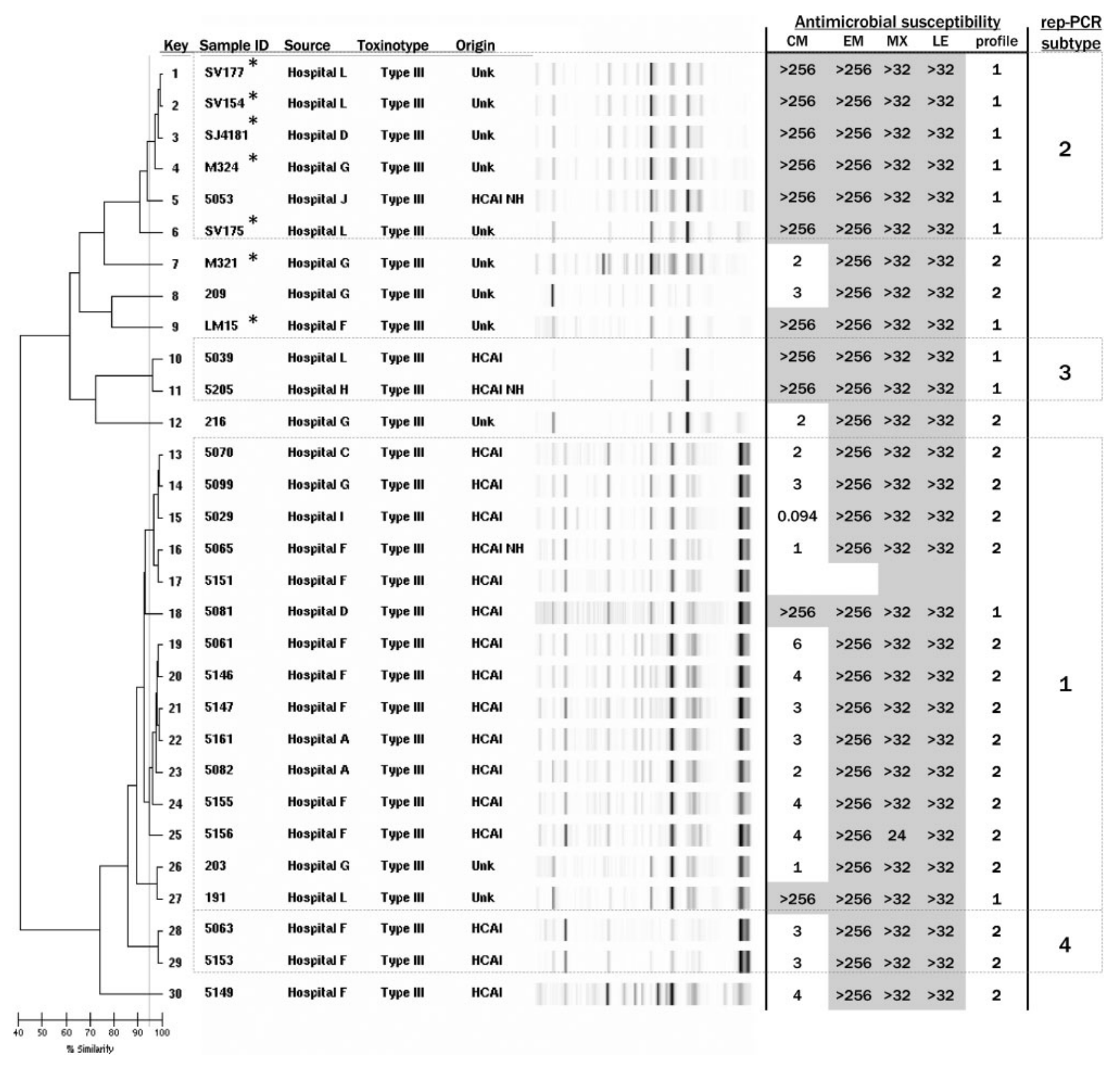

Fig. 2. rep-PCR dendrogram including electropherograms of all isolates of ribotype 027 from 2006 (marked with asterisks) and 2009. rep-PCR subtypes with $>90 \%$ similarity are identified (by the dashed boxes). Major subtypes (1 and 2 ) were assigned where three or more isolates clustered together; minor subtypes ( 3 and 4) were assigned where pairs of isolates were similar. Isolates are identified by hospital source, toxinotype and origin of infection ( $\mathrm{HCAl}$, health-care-associated infection; $\mathrm{HCAl} \mathrm{NH}$, health-care-associated infection from a nursing home; Unk, unknown origin). Antimicrobial-susceptibility profiles were assigned on the basis of resistance (shaded) to clindamycin (CM), erythromycin (EM), moxifloxacin (MX) and levofloxacin (LE).

number of ribotype 078 isolates or were not supported directly by alternative typing methods. Bakker et al. (2010) determined that out of three ribotype 078 isolates from Ireland, two were identical and one was genetically unrelated based on a single locus variation (summed tandem repeat differences $>10$ ) after MLVA analysis. Two of the Irish isolates in this study were isolated in 2008, when an outbreak of ribotype 078 was reported (Burns et al., 2010a), and therefore may be more likely to be clonal. In addition, all three Irish isolates reported by Bakker et al. (2010) were found to be tetracycline susceptible and, as shown here, isolates with similar antimicrobial-susceptibility profiles are more likely to be related by rep-PCR.

The diversity identified in ribotype 078 rep-PCR subtypes could be explained by reports that ribotype 078 is more 


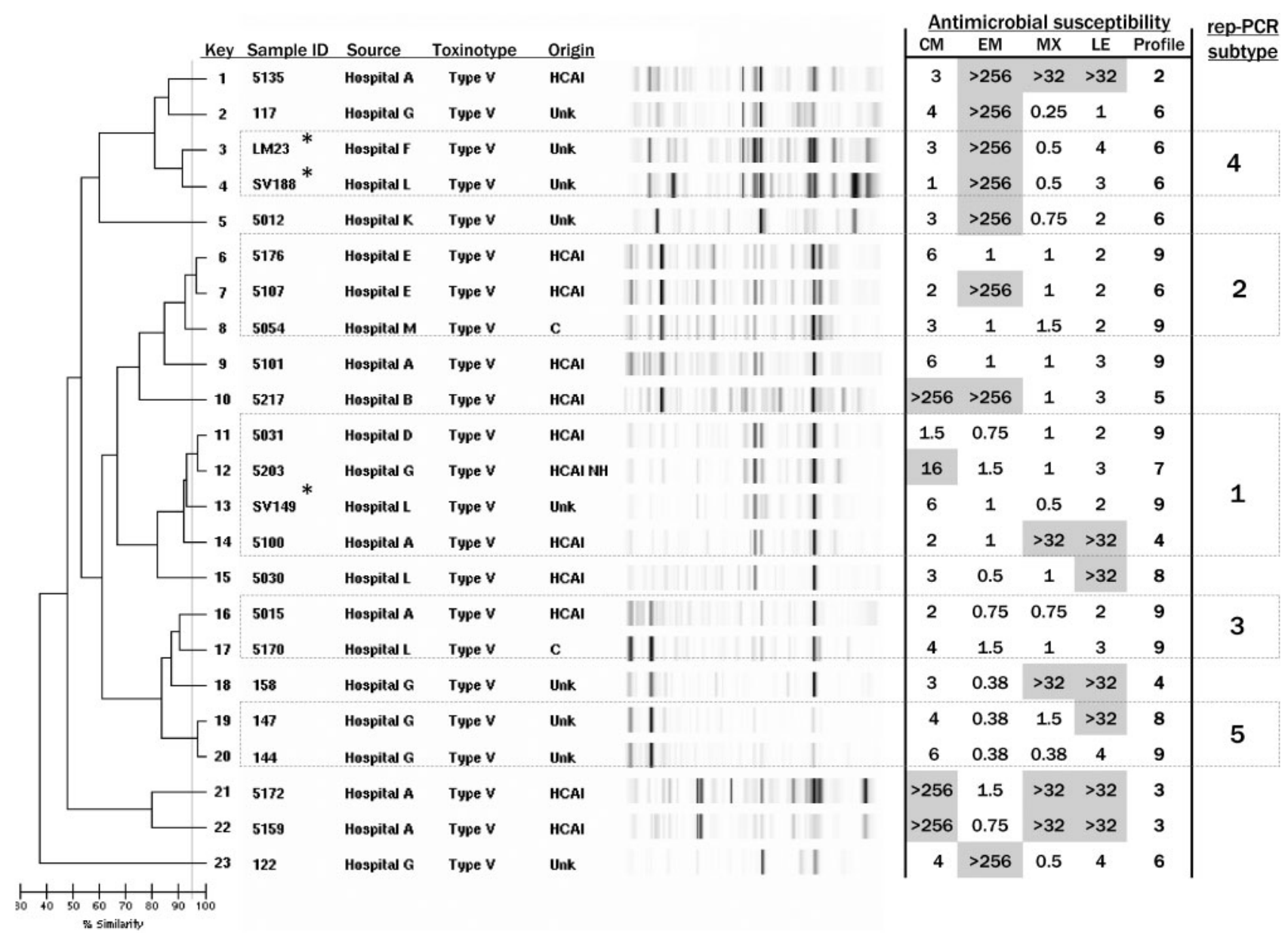

Fig. 3. rep-PCR dendrogram including electropherograms of all isolates of ribotype 078 from 2006 (marked with asterisks) and 2009. rep-PCR subtypes with $>90 \%$ similarity are identified (by the dashed boxes). Major ( 1 and 2$)$ and minor subtypes (3, 4 and 5) were assigned as detailed in Fig. 2. Isolates are identified by hospital source, toxinotype and origin of infection (HCAl, health-care-associated infection; HCAI NH, health-care-associated infection from a nursing home; $\mathrm{C}$, community-acquired; Unk, unknown origin). Antimicrobial-susceptibility profiles were assigned on the basis of resistance (shaded) to clindamycin $(\mathrm{CM})$, erythromycin (EM), moxifloxacin (MX) and levofloxacin (LE).

commonly associated with community onset of disease and that this ribotype is more commonly found outside the health-care environment (Notermans et al., 2008). Transmission from environment-to-person may mean that ribotype 078 isolates have not yet fully adapted to the human niche for clonal expansion, although reports of CDI due to ribotype 078 are becoming more frequent (Burns et al., 2010a; Goorhuis et al., 2008a; Rupnik et al., 2008). It could therefore be suggested that ribotype 027 infections are more likely than those of ribotype 078 to be transmitted by person-to-person routes, ensuring a clonal genetic identity within the population of the former.

We postulate that the degree of rep-PCR type variability within PCR ribotypes means that it is not yet possible to directly apply the results of rep-PCR to ribotyping in every case without conducting the two typing methods simultaneously. However, by increasing the numbers of isolates analysed by both methods and uploading the profiles into a central online DiversiLab library, future users of this technique may be able to reliably define subtypes and ribotypes by comparing their profiles to a comprehensive library.

\section{Correlation with antimicrobial-susceptibility profiles}

Analysis of the antimicrobial-susceptibility profiles for ribotype 027 identified two different profiles. Isolates of a similar susceptibility profile generally clustered together and isolates of subtype 1 were significantly more likely to be clindamycin sensitive $(P<0.05)$ than those in subtype 2 , suggesting a strong correlation between subtypes and clindamycin resistance. Of the four isolates from 2009 that were resistant to clindamycin, two were cultured from patients for whom the origin of infection was a nursing home. 
Ribotype 078 isolates were categorized into eight very diverse susceptibility profiles that correlated with subtyping in only two instances (subtypes 3 and 4). This diversity within ribotype 078 subtypes suggests that isolates may have acquired novel mechanisms of resistance, possibly due to selection pressures that are encountered in a variety of environmental reservoirs and not normally seen in human reservoirs. Of particular note is the presence of clindamycin resistance in the absence of erythromycin resistance in two isolates of ribotype 078. This unusual phenotype has been reported in Streptococcus pneumoniae and in Enterococcus faecium associated with the $\operatorname{lin} B$ gene, although it has yet to be confirmed in C. difficile (Bozdogan et al., 1999; Montagnani et al., 2007).

Resistance to clindamycin is most commonly associated with the insertion of one or more genes such as ermB located on transposons into the $C$. difficile genome, which may have altered the rep-PCR fingerprint profiles of these isolates. Correlation between molecular typing and clindamycin resistance has also been seen in ribotype 027 isolates by MLVA (Drudy et al., 2008) and ribotype 001 by randomly amplified polymorphic DNA (Fawley et al., 2003) with distinct resistant and susceptible clones identified.

\section{Comparison within a hospital}

Comparisons between ribotype 027 subtypes within hospital F confirmed the genetic and antimicrobialsusceptibility profile similarity (Fig. 4a). Isolates clustered into two subtypes on the basis of a $90 \%$ similarity threshold, with two outlying isolates, one obtained in 2009 and another from 2006, unrelated to the clusters.

Comparisons between ribotype 078 subtypes within hospital A confirmed the genetic and antimicrobialsusceptibility profile diversity (Fig. 4b). The closest

(a)

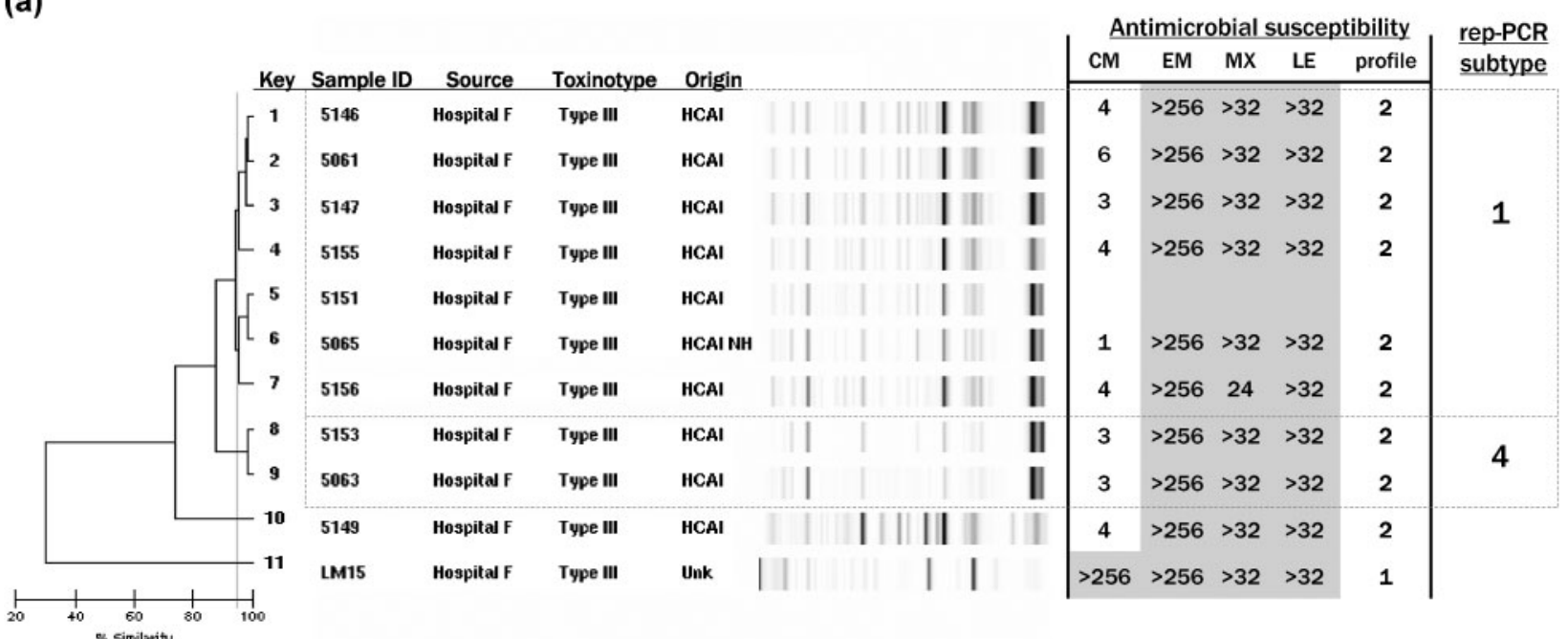

(b)

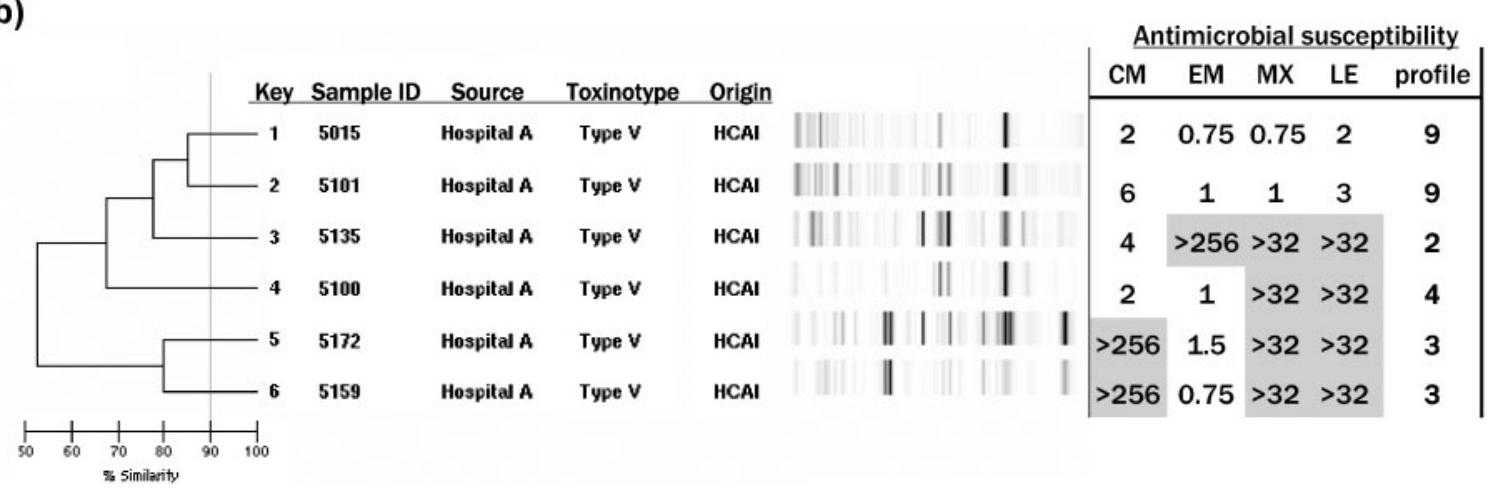

Fig. 4. rep-PCR dendrograms of isolates of ribotype 027 from hospital $F(a)$ and isolates of ribotype 078 from hospital $A$ (b). rep-PCR subtypes with $>90 \%$ similarity are identified (by the dashed boxes). Major (1) and minor (4) subtypes were assigned as detailed in Fig. 2. Isolates are identified by hospital source, toxinotype and origin of infection (HCAl, health-care-associated infection; HCAI NH, health-care-associated infection from a nursing home; Unk, unknown origin). Antimicrobial-susceptibility profiles were assigned on the basis of resistance (shaded) to clindamycin (CM), erythromycin (EM), moxifloxacin (MX) and levofloxacin (LE). 
similarity between isolates was $85 \%$. Two susceptibility profiles were unique to this hospital, characterized by the presence of both fluoroquinolone and $\mathrm{MLS}_{\mathrm{B}}$ resistance, which is unusual in ribotype 078 isolates.

\section{Comparison between ribotyped isolates from 2006 and 2009}

Members of the major subtype of ribotype 027 isolates analysed from 2006 clustered closely together (subtype 2; Fig. 2), but were unrelated to the predominant subtype circulating in 2009 (all 027 isolates from 2006 marked with an asterisk in Fig. 2). Clindamycin resistance was significantly more common in ribotype 027 isolates from 2006 than in the prevalent subtype in $2009(P<0.01)$, which were predominantly clindamycin susceptible. A shift in the predominant ribotype 027 subtype has occurred, characterized by the loss of clindamycin resistance, and the new susceptible subtype has spread nationwide. Restriction and pre-authorization for use of clindamycin during nosocomial outbreaks of CDI has proven to be an effective measure to promptly limit outbreaks (Climo et al., 1998; Pear et al., 1994). Implementation of these policies was unlikely, however, to have selected for the recent dominance of the clindamycin-sensitive subtype as clindamycin usage in Ireland is relatively low [0.46 defined daily dose per 100 bed days in 2006 and 0.49 defined daily dose per 100 bed days in 2008 (HPSC-HSE, 2008)]. The most likely cause therefore is the introduction of a clindamycin-resistant strain in 2006 that was initially successful amongst other Irish strains, but was gradually replaced by a sensitive strain without the selection pressure of antibiotics. The prescribing policy in nursing homes, however, may be less restrictive, favouring the emergence of clindamycin-resistant isolates from recent infections that originated in these facilities.

Comparisons between ribotype 078 isolates from 2006 (marked with an asterisk in Fig. 3) and 2009 identified close relationships between isolates (subtype 1; Fig. 3) suggesting the persistence of certain subtypes with very little genetic change. Many new subtypes have, however, been introduced since 2006 that are radically diverse both genetically and in their antimicrobial-susceptibility profiles.

\section{Conclusion}

We investigated the heterogeneity of clinical C. difficile isolates of ribotypes 027 and 078 by a semi-automated DiversiLab rep-PCR method to investigate the epidemiology of these clinically important strains within healthcare facilities. Ribotype 027 isolates were significantly more likely to be closely related to each other than ribotype 078 isolates. Ribotype 078 isolates also exhibited a wider range of antimicrobial-susceptibility profiles, suggesting that ribotype 078 infections may have originated from a variety of non-health-care and environmental sources. A shift in the predominant circulating subtype of ribotype 027 was identified between 2006 and 2009 from a clindamycinresistant subtype to clindamycin-susceptible subtype similar to PFGE type NAP-1 that is now widespread within Ireland. Preventing the emergence of novel antimicrobial-resistant subtypes, mainly from community and environmental sources, should also be a priority and implemented by employing strict antimicrobial-usage policies in general practice and food production methods.

\section{ACKNOWLEDGEMENTS}

The research outlined in this paper was funded by the Health Research Board, Ireland, and the Health Protection Surveillance Centre, Dublin, Ireland. We thank the participating infection prevention and control teams, surveillance and microbiology laboratory scientists, Dr E. Kuijper and colleagues in Leiden University Medical Centre, The Netherlands, Dr Jon Brazier and colleagues at the Anaerobe Reference Laboratory, Cardiff, UK, for assistance with ribotyping, and Professor Maja Rupnik and colleagues at the Institute of Public Health Maribor, Maribor, Slovenia, for assistance with toxinotyping.

\section{REFERENCES}

Bakker, D., Corver, J., Harmanus, C., Goorhuis, A., Keessen, E. C., Fawley, W. N., Wilcox, M. H. \& Kuijper, E. J. (2010). Relatedness of human and animal Clostridium difficile PCR ribotype 078 isolates determined on the basis of multilocus variable-number tandemrepeat analysis and tetracycline resistance. J Clin Microbiol 48, 37443749.

Bozdogan, B., Berrezouga, L., Kuo, M. S., Yurek, D. A., Farley, K. A., Stockman, B. J. \& Leclercq, R. (1999). A new resistance gene, linB, conferring resistance to lincosamides by nucleotidylation in Enterococcus faecium HM1025. Antimicrob Agents Chemother 43, 925-929.

Brazier, J. S., Raybould, R., Patel, B., Duckworth, G., Pearson, A., Charlett, A., Duerden, B. I. \& the HPA Regional Microbiology Network (2008). Distribution and antimicrobial susceptibility patterns of Clostridium difficile PCR ribotypes in English hospitals, 2007-08. Euro Surveill 13, pii:19000.

Burns, K., Morris-Downes, M., Fawley, W. N., Smyth, E., Wilcox, M. H. \& Fitzpatrick, F. (2010a). Infection due to C. difficile ribotype 078: first report of cases in the Republic of Ireland. J Hosp Infect 75, 287-291.

Burns, K., Skally, M., Solomon, K., Scott, L., McDermott, S., O’Flanagan, D., Fanning, S., Kyne, L., Fenelon, L. \& Fitzpatrick, F. (2010b). Clostridium difficile infection in the Republic of Ireland: results of a 1-month national surveillance and ribotyping project, March 2009. Infect Control Hosp Epidemiol 31, 1085-1087.

Climo, M. W., Israel, D. S., Wong, E. S., Williams, D., Coudron, P. \& Markowitz, S. M. (1998). Hospital-wide restriction of clindamycin: effect on the incidence of Clostridium difficile-associated diarrhea and cost. Ann Intern Med 128, 989-995.

CLSI (2007). Methods for Antimicrobial Susceptibility Testing of Anaerobic Bacteria, approved standard, M11-A7. Wayne, PA: Clinical and Laboratory Standards Institute.

Debast, S. B., Van Leengoed, L. A., Goorhuis, A., Harmanus, C., Kuijper, E. J. \& Bergwerff, A. A. (2009). Clostridium difficile PCR ribotype 078 toxinotype $\mathrm{V}$ found in diarrhoeal pigs identical to isolates from affected humans. Environ Microbiol 11, 505-511.

Drudy, D., Goorhuis, B., Bakker, D., Kyne, L., Van den Berg, R., Fenelon, L., Fanning, S. \& Kuijper, E. J. (2008). Clindamycin-resistant 
clone of Clostridium difficile PCR ribotype 027, Europe. Emerg Infect Dis 14, 1485-1487.

Fawley, W. N., Freeman, J. \& Wilcox, M. H. (2003). Evidence to support the existence of subgroups within the UK epidemic Clostridium difficile strain (PCR ribotype 1). J Hosp Infect 54, 74-77.

Fawley, W. N., Freeman, J., Smith, C., Harmanus, C., Van den Berg, R. J., Kuijper, E. J. \& Wilcox, M. H. (2008). Use of highly discriminatory fingerprinting to analyze clusters of Clostridium difficile infection cases due to epidemic ribotype 027 strains. J Clin Microbiol 46, 954-960.

Goorhuis, A., Bakker, D., Corver, J., Debast, S. B., Harmanus, C., Notermans, D. W., Bergwerff, A. A., Dekker, F. W. \& Kuijper, E. J. (2008a). Emergence of Clostridium difficile infection due to a new hypervirulent strain, polymerase chain reaction ribotype 078. Clin Infect Dis 47, 1162-1170.

Goorhuis, A., Debast, S. B., Van Leengoed, L. A. M. G., Harmanus, C., Notermans, D. W., Bergwerff, A. A. \& Kuijper, E. J. (2008b). Clostridium difficile PCR ribotype 078: an emerging strain in humans and in pigs? J Clin Microbiol 46, 1157-1158.

Healy, M., Huong, J., Bittner, T., Lising, M., Frye, S., Raza, S., Schrock, R., Manry, J., Renwick, A. \& other authors (2005). Microbial DNA typing by automated repetitive-sequence-based PCR. J Clin Microbiol 43, 199-207.

Hensgens, M. P., Goorhuis, A., Notermans, D. W., Van Benthem, B. H. \& Kuijper, E. J. (2009). Decrease of hypervirulent Clostridium difficile PCR ribotype 027 in the Netherlands. Euro Surveill 14, pii:19402.

HPSC-HSE (2008). Consumption of Antibiotics in Public Acute Hospitals in Ireland, 2008. Dublin: Health Protection Surveillance Centre and Health Service Executive. http://www.hpsc.ie/hpsc/A-Z/ MicrobiologyAntimicrobialResistance/EuropeanSurveillanceofAntimicrobial ConsumptionESAC/SurveillanceReports/File,3889,en.pdf

Jhung, M. A., Thompson, A. D., Killgore, G. E., Zukowski, W. E., Songer, G., Warny, M., Johnson, S., Gerding, D. N., McDonald, L. C. \& Limbago, B. M. (2008). Toxinotype V Clostridium difficile in humans and food animals. Emerg Infect Dis 14, 1039-1045.

Johnson, S., Samore, M. H., Farrow, K. A., Killgore, G. E., Tenover, F. C., Lyras, D., Rood, J. I., DeGirolami, P., Baltch, A. L. \& other authors (1999). Epidemics of diarrhea caused by a clindamycinresistant strain of Clostridium difficile in four hospitals. N Engl J Med 341, 1645-1651.

Keel, K., Brazier, J. S., Post, K. W., Weese, S. \& Songer, J. G. (2007). Prevalence of PCR ribotypes among Clostridium difficile isolates from pigs, calves, and other species. J Clin Microbiol 45, 1963-1964.

Killgore, G., Thompson, A., Johnson, S., Brazier, J., Kuijper, E., Pepin, J., Frost, E. H., Savelkoul, P., Nicholson, B. \& other authors (2008). Comparison of seven techniques for typing international epidemic strains of Clostridium difficile: restriction endonuclease analysis, pulsed-field gel electrophoresis, PCR-ribotyping, multilocus sequence typing, multilocus variable-number tandem-repeat analysis, amplified fragment length polymorphism, and surface layer protein A gene sequence typing. J Clin Microbiol 46, 431-437.

Kuijper, E. J., Coignard, B. \& Tüll, P. on behalf of the ESCMID Study Group for Clostridium difficile (ESGCD), EU Member States \& the European Centre for Disease Prevention and Control (ECDC) (2006). Emergence of Clostridium difficile-associated disease in North America and Europe. Clin Microbiol Infect 12 (Suppl. 6), 2-18.

Kuijper, E. J., Coignard, B., Brazier, J. S., Suetens, C., Drudy, D., Wiuff, C., Pituch, H., Reichert, P., Schneider, F. \& other authors
(2007). Update of Clostridium difficile-associated disease due to PCR ribotype 027 in Europe. Euro Surveill 12, E1-E2.

Kuijper, E. J., Barbut, F., Brazier, J. S., Kleinkauf, N., Eckmanns, T., Lambert, M. L., Drudy, D., Fitzpatrick, F., Wiuff, C. \& other authors (2008). Update of Clostridium difficile infection due to PCR ribotype 027 in Europe, 2008. Euro Surveill 13, pii:18942.

Kuijper, E. J., Van den Berg, R. J. \& Brazier, J. S. (2009). Comparison of molecular typing methods applied to Clostridium difficile. Methods Mol Biol 551, 159-171.

Lin, Y. C., Huang, Y. T., Tsai, P. J., Lee, T. F., Lee, N. Y., Liao, C. H., Lin, S. Y., Ko, W. C. \& Hsueh, P. R. (2011). Antimicrobial susceptibilities and molecular epidemiology of clinical isolates of Clostridium difficile in Taiwan. Antimicrob Agents Chemother 55, 1701-1705.

McDonald, L. C., Killgore, G. E., Thompson, A., Owens, R. C., Jr, Kazakova, S. V., Sambol, S. P., Johnson, S. \& Gerding, D. N. (2005). An epidemic, toxin gene-variant strain of Clostridium difficile. $N$ Engl J Med 353, 2433-2441.

Montagnani, F., Zanchi, A., Stolzuoli, L., Croci, L. \& Cellesi, C. (2007). Clindamycin-resistant Streptococcus pneumoniae. Emerg Infect Dis 13, 801-802.

Northey, G., Gal, M., Rahmati, A. \& Brazier, J. S. (2005). Subtyping of Clostridium difficile PCR ribotype 001 by REP-PCR and PFGE. J Med Microbiol 54, 543-547.

Notermans, D. W., Van der Kooi, T. I., Goorhuis, A., Debast, S. B., Van Benthem, B. H. \& Kuijper, E. J. (2008). [Epidemiology of Clostridium difficile PCR ribotype 027 in the Netherlands 2005present and the emergence of other subtypes]. Ned Tijdschr Geneeskd 152, 1937-1940 (in Dutch).

Pasanen, T., Kotila, S. M., Horsma, J., Virolainen, A., Jalava, J., Ibrahem, S., Antikainen, J., Mero, S., Tarkka, E. \& other authors (2011). Comparison of repetitive extragenic palindromic sequencebased PCR with PCR ribotyping and pulsed-field gel electrophoresis in studying the clonality of Clostridium difficile. Clin Microbiol Infect 17, 166-175.

Pear, S. M., Williamson, T. H., Bettin, K. M., Gerding, D. N. \& Galgiani, J. N. (1994). Decrease in nosocomial Clostridium difficile-associated diarrhea by restricting clindamycin use. Ann Intern Med 120, 272277.

Rahmati, A., Gal, M., Northey, G. \& Brazier, J. S. (2005). Subtyping of Clostridium difficile polymerase chain reaction (PCR) ribotype 001 by repetitive extragenic palindromic PCR genomic fingerprinting. $J$ Hosp Infect 60, 56-60.

Rupnik, M., Avesani, V., Janc, M., Von Eichel-Streiber, C. \& Delmée, M. (1998). A novel toxinotyping scheme and correlation of toxinotypes with serogroups of Clostridium difficile isolates. J Clin Microbiol 36, 2240-2247.

Rupnik, M., Widmer, A., Zimmermann, O., Eckert, C. \& Barbut, F. (2008). Clostridium difficile toxinotype V, ribotype 078, in animals and humans. J Clin Microbiol 46, 2146.

Smith, A. (2005). Outbreak of Clostridium difficile infection in an English hospital linked to hypertoxin-producing strains in Canada and the US. Euro Surveill 10, E050630.2.

Spigaglia, P. \& Mastrantonio, P. (2003). Evaluation of repetitive element sequence-based PCR as a molecular typing method for Clostridium difficile. J Clin Microbiol 41, 2454-2457.

Stubbs, S. L., Brazier, J. S., O'Neill, G. L. \& Duerden, B. I. (1999). PCR targeted to the 16S-23S rRNA gene intergenic spacer region of Clostridium difficile and construction of a library consisting of 116 different PCR ribotypes. J Clin Microbiol 37, 461-463. 